\title{
Closing the Loop on Automotive Carbon Fiber Prepreg Manufacturing Scrap
}

Date: December 2, 2021

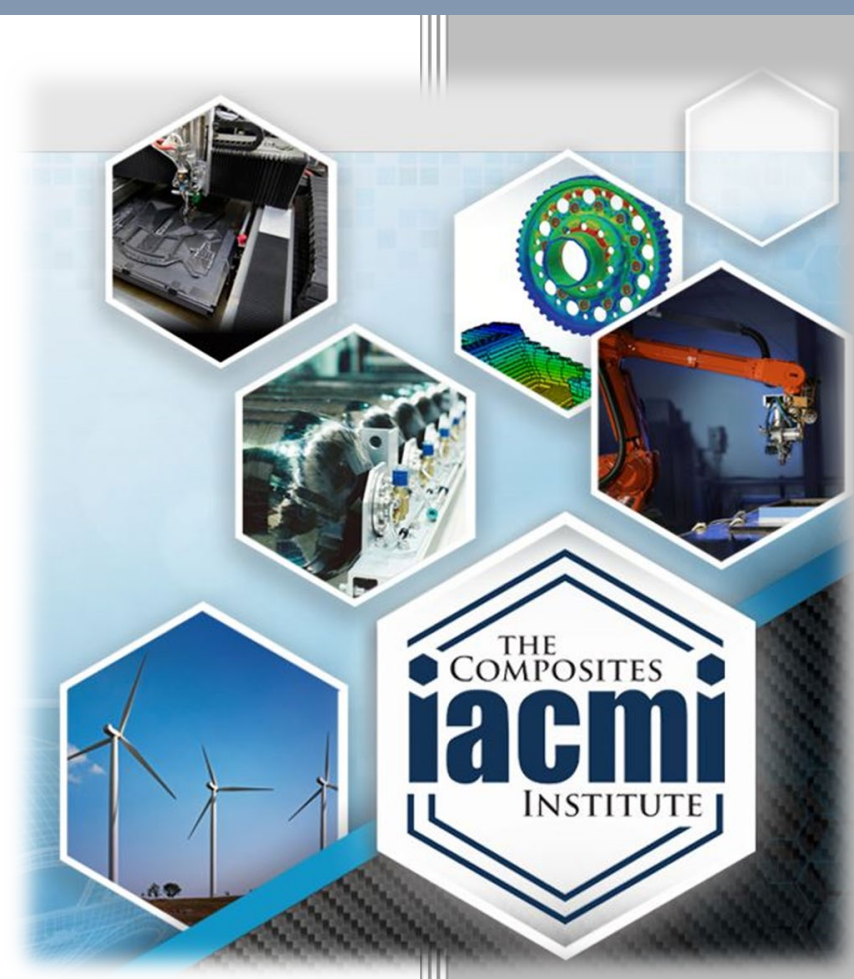

\begin{tabular}{|c|}
\hline Final Technical Report \\
PA16-0349-6.20-01 \\
\hline
\end{tabular}

Approved for Public Release.

Distribution is Unlimited.

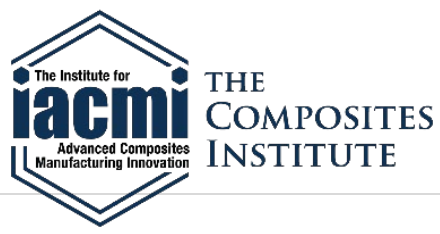

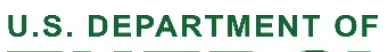




\section{DOCUMENT AVAILABILITY}

Reports produced after January 1, 1996, are generally available free via US Department of Energy (DOE) SciTech Connect.

Website http://www.osti.gov/scitech/

Reports produced before January 1, 1996, may be purchased by members of the public from the following source:

National Technical Information Service

5285 Port Royal Road

Springfield, VA 22161

Telephone 703-605-6000 (1-800-553-6847)

TDD 703-487-4639

Fax 703-605-6900

E-mailinfo@ntis.gov

Website http://www.ntis.gov/help/ordermethods.aspx

Disclaimer: "The information, data, or work presented herein was funded in part by an agency of the United States Government. Neither the United States Government nor any agency thereof, nor any of their employees, makes any warranty, express or implied, or assumes any legal liability or responsibility for the accuracy, completeness, or usefulness of any information, apparatus, product, or process disclosed, or represents that its use would not infringe privately owned rights. Reference herein to any specific commercial product, process, or service by trade name, trademark, manufacturer, or otherwise does not necessarily constitute or imply its endorsement, recommendation, or favoring by the United States Government or any agency thereof. The views and opinions of authors expressed herein do not necessarily state or reflect those of the United States Government or any agency thereof." 


\section{Closing the Loop on Automotive Carbon Fiber Prepreg Manufacturing Scrap}

Principal Investigator: Sean Kline

Organization: Vartega Inc

Address: $15000 \mathrm{~W} 44^{\text {th }}$ Avenue Suite F Golden CO 80403

Phone: $844-827-8342$

Email: Sean@vartega.com

Co-authors:

Sean P. Kline ${ }^{1}$, Andrew T. Maxey ${ }^{1}$ Peter E. Caltagirone ${ }^{2}$, Kenneth X. Steirer ${ }^{2}$, Dylan Cousins ${ }^{2}$, Aaron P. Stebner ${ }^{2}$ Ryan S. Ginder ${ }^{3}$, Soydan Ozcan ${ }^{4}, \mathrm{Kai}_{\mathrm{Li}}{ }^{5}$, Alex M. Gay ${ }^{6}$, Jared Stonecash ${ }^{7}$, Doug Bradley

${ }^{1}$ Vartega Inc.; Golden, CO 80403; USA

${ }^{2}$ Colorado School of Mines; Departments of Mechanical Engineering, Materials Science; Golden, CO 80401, USA

${ }^{3}$ University of Tennessee Knoxville; Department of Mechanical, Aerospace and Biomedical Engineering; Knoxville, TN 37996 USA

${ }^{4}$ Oak Ridge National Laboratory; Manufacturing Science Division; Oak Ridge, TN 37831 USA

${ }^{5}$ Oak Ridge National Laboratory; Building and Transportation Science division; Oak Ridge, TN, 37830 USA

${ }^{6}$ University of Dayton Research Institute; Structural Materials Division; Dayton, OH 45469 USA

${ }^{7}$ Michelman Inc.; Cincinnati, OH 45236; USA

${ }^{8}$ Michigan State University, Chemical Engineering and Materials Science Department, Composite Materials \& Structures Center, Scale-up Research Facility

Date Published: (December, 2021)

Prepared by:

Institute for Advanced Composites Manufacturing Innovation

Knoxville, TN 37932

Managed by Collaborative Composite Solutions, Inc.

For the

U.S. DEPARTMENT OF ENERGY

Under contract DE- EE0006926

Project Period:

$(06 / 2018-09 / 2021)$

Approved For Public Release 


\section{TABLE OF CONTENTS}

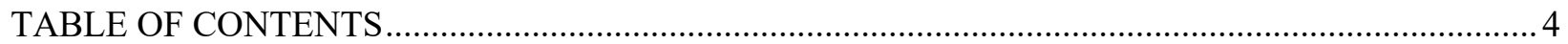

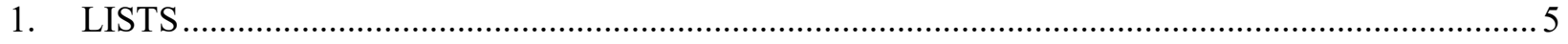

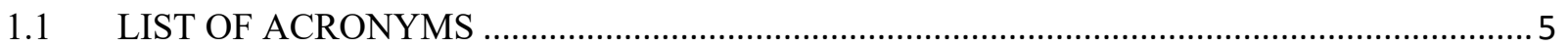

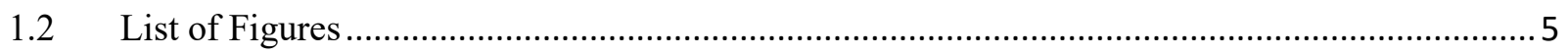

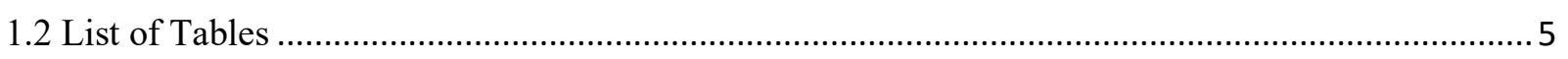

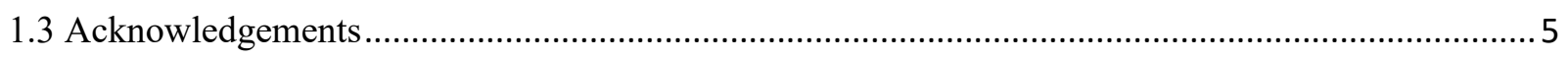

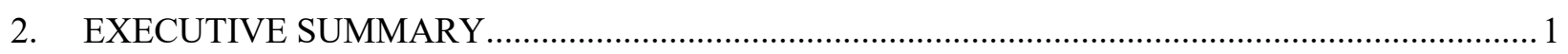

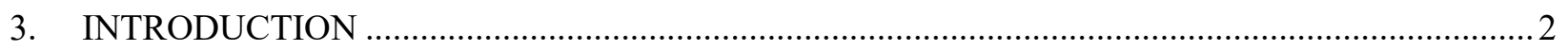

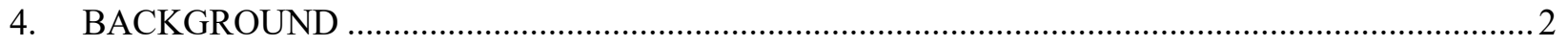

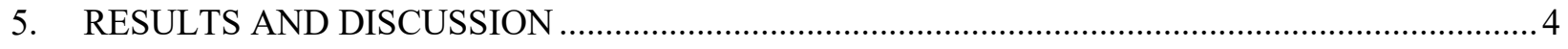

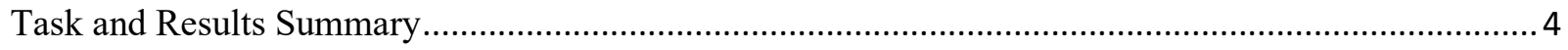

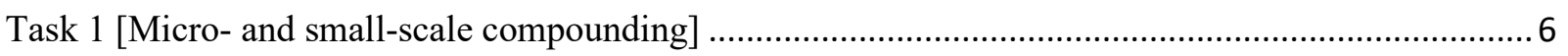

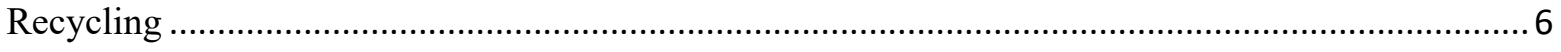

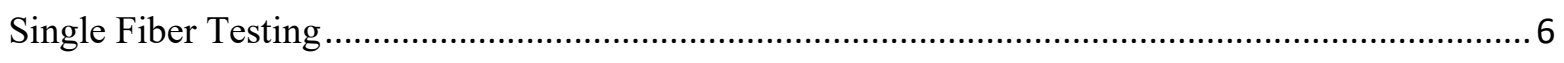

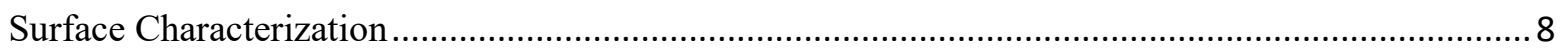

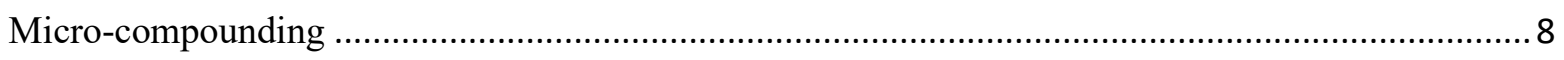

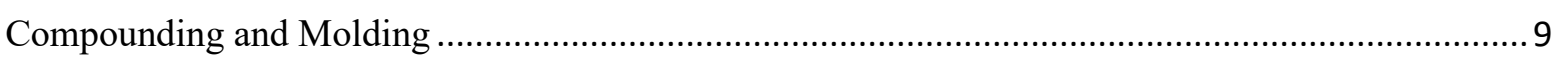

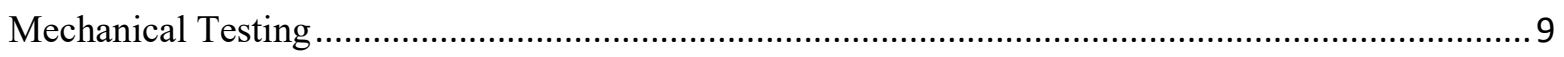

Fracture Surface Scanning Electron Microscopy Evaluation ....................................................... 10

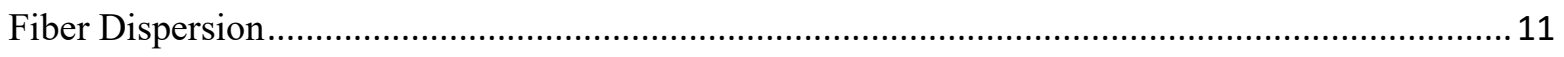

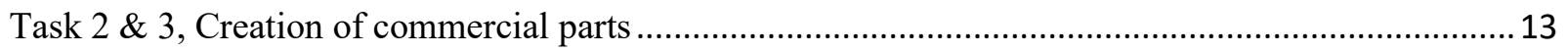

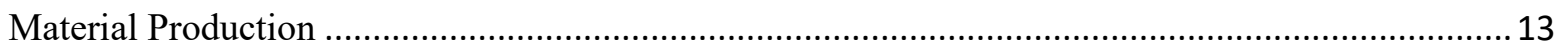

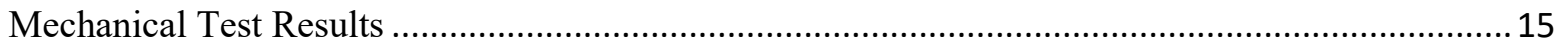

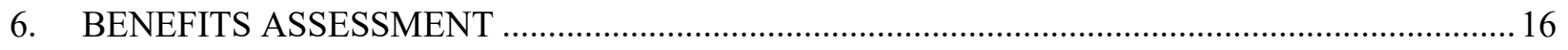

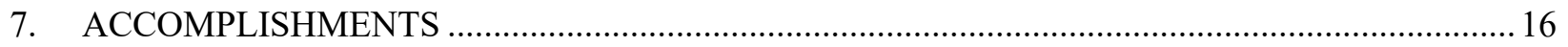

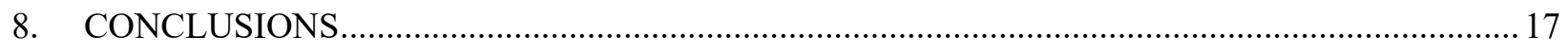

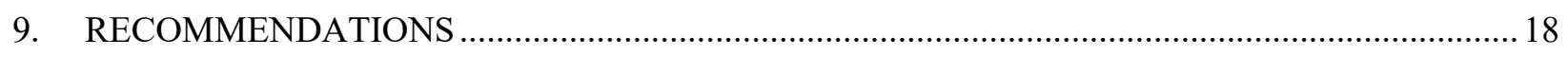

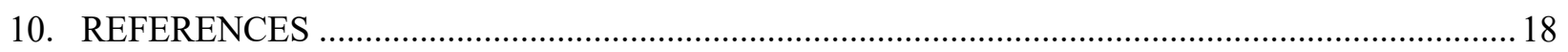




\section{LISTS \\ 1.1 LIST OF ACRONYMS \\ CFRP Carbon fiber-reinforced polymer \\ FLD Fiber length distribution \\ FVF Fiber volume fraction \\ GNG Go / no-go \\ IACMI Institute for Advanced Composites Manufacturing Innovation \\ ORNL Oak Ridge National Laboratory \\ PA66 Polyamide 6,6 \\ rCF Recycled carbon fiber \\ DRCFTP Discontinuous recycled carbon fiber thermoplastic \\ SEM Scanning Electron microscope \\ SuRF Scale-up Research Facility \\ UDRI University of Dayton Research Institute \\ VCF Virgin carbon fiber \\ XCT X-ray computed tomography \\ XPS X-ray photoelectron spectroscopy}

\subsection{List of Figures}

Figure 1: (a) Prepreg before recycling and (b) dry fiber after recycling

Figure 2: Measured average CF filament densities (a-true volumetric, b-approximate linear), calculated average diameters (assuming cylindrical fiber geometry), and tensile properties with error bars denoting standard error. For $\mathrm{vCF}, \mathrm{n}=19$. For $\mathrm{rCF}, \mathrm{n}=18$.

Figure 3: SEM images of (a, b) BASF vCF, (c, d) A-02 rCF, and (e, f) A-05 rCF fracture surfaces.......... 11

Figure 4: Voids detected by XCT in the rCF HBF-37_14 sample with (a) front, (b) side, and (c) top

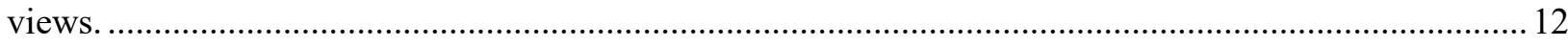

Figure 5: FVF and angular orientation measurements of (a, d) A3WC8-BASF, (b, e) HBF-37_10, and (c,

f) HBF-37_14 samples, respectively, from XCT image analysis. …………………………………....... 13

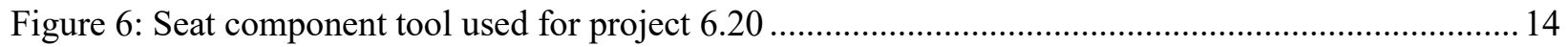

Figure 7: Fully filled components molded from Task 3 material .......................................................... 14

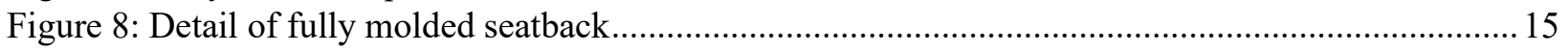

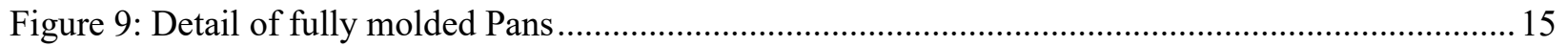

\subsection{List of Tables}

Table 1: Mechanical property comparisons between compounded $\mathrm{rCF}$ and commercial material. ............10

Table 2: Mechanical property results for Task 2 and Task 3 material..................................................... 15

\subsection{Acknowledgements}

The information, data, or work presented herein was funded in part by the Office of Energy Efficiency and Renewable Energy (EERE), U.S. Department of Energy, under Award DE- EE0006926

The authors acknowledge the Institute for Advanced Composites Manufacturing Innovation (IACMI) for their administrative support of this collaboration. The authors also acknowledge the Colorado Office of Economic Development and International Trade (OEDIT) for their financial support through grants CTGG1 2018-1981 and CTGG1 2018-0632, as well as the Advanced Industries Accelerator Program and JobsOhio for their support of the project. The authors thank Oak Ridge National Laboratory personnel David McConnell for assistance with filament characterization, Harry Meyer III for 
assistance with XPS testing, and Denver McGrady for assistance with FLD measurements as well as Professor Uday Vaidya's team at the University of Tennessee Knoxville for their assistance with impact test specimen preparation. The authors also acknowledge Ford and BASF for their support of this project and contributions to the carbon fiber industry, making the research in this paper possible.

This manuscript has been authored in part by UT-Battelle, LLC under Contract No. DE-AC0500OR22725 with the U.S. Department of Energy. The publisher, by accepting the article for publication, acknowledges that the United States Government retains a non-exclusive, paid-up, irrevocable, worldwide license to publish or reproduce the published form of this manuscript, or allow others to do so, for United States Government purposes. The Department of Energy will provide public access to these results of federally sponsored research in accordance with the DOE Public Access Plan (http://energy.gov/downloads/doe-public-access-plan). The information, data, or work presented herein was funded in part by the Office of Energy Efficiency and Renewable Energy (EERE), U.S. Department of Energy, under Award Number DE-EE0006926. The information, data, or work presented herein was funded in part by an agency of the United States Government. Neither the United States Government nor any agency thereof, nor any of their employees, makes any warranty, express or implied, or assumes any legal liability or responsibility for the accuracy, completeness, or usefulness of any information, apparatus, product, or process disclosed, or represents that its use would not infringe privately owned rights. Reference herein to any specific commercial product, process, or service by trade name, trademark, manufacturer, or otherwise does not necessarily constitute or imply its endorsement, recommendation, or favoring by the United States Government or any agency thereof. The views and opinions of the authors expressed herein do not necessarily state or reflect those of the United States Government or any agency thereof. 


\section{EXECUTIVE SUMMARY}

The project demonstrated how to "close the loop" on carbon fiber by integrating industrial carbon fiber scrap into new functional components in an automotive lightweighting application. The project serves as a validation of discontinuous recycled carbon fiber in a commercial context, while generating comprehensive material data throughout the production chain.

To this end, the project exhibited increasing complexity as material evaluation progressed from benchtop to commercial scale through full-scale part production, with key material properties thoroughly characterized throughout the process. Of particular focus was the form of the fiber that was fed into compounding, as recycled fiber has historically been problematic to feed at commercial-scale.

Carbon fiber is energy-intensive to manufacture, so reuse of existing fiber material can reduce costs and increase sustainability. Additionally, by integrating recovered short fiber into a thermoplastic, regrind processes can be used to provide feedstock for later generations of product. While regrind plastics are not "infinitely recyclable", reusing the manufacturing scrap over several generations of products can greatly increase material sustainability and lower the fractional embodied energy of each successive product. As such, this project supports the IACMI technical goals of (1) $25 \%$ lower carbon fiber-reinforced polymer (CFRP) cost, (2) 50\% reduction in CFRP embodied energy, and (3) 80\% composite recyclability into useful products.

The initial stage of the project involved downselecting surface treatment (sizing) chemistries. Sizing evaluations were performed on Vartega's chemically recycled intermediate modulus fiber along with standard modulus dry scrap which was oversized with sizing provided by Michelman. More dramatic improvements from sizing were found on the standard rather than the intermediate modulus fibers.

The strength of the chemically recycled individual fibers were evaluated by Michelman and ORNL through single fiber testing and found to be comparable to similarly evaluated virgin fibers.

UDRI's mechanical testing on injection molded test specimens identified similar mechanical properties and fiber distribution relative to benchmark specimens. Additional surface chemistry tests and visualizations were performed by the Colorado School of Mines to confirm close conformance between the benchmark and recycled-fiber specimens. As the mechanical test results exceeded the $80 \%$ threshold established as the go/no-go (GNG), the project scale was increased to use commercial-scale equipment that would both better characterize the manufacturing utility of the target product format and allow qualitative assessment of a complex commercial part.

An upscaled compounding evaluation was performed with a $27 \mathrm{~mm}$ twin-screw compounding extruding using oversized standard modulus fibers that were formatted to improve bulk solids transfer. The project team anticipated that milestone mechanical benchmarks could be achieved given the favorable performance of the sized standard modulus material identified in the initial micro-compounding trials. While the mechanical performance did meet the milestone target for that phase of the project, mechanical properties for this standard modulus-based compound were still less than those of the Ford specification.

To compare the performance, the project team oversized intermediate modulus dry fibers and compounded them with the project resin at BASF using a $40 \mathrm{~mm}$ compounder. Test specimen mechanical performance exceeded the targets laid out in both the project milestone and the Ford specification. A series of prototype parts were successfully molded, albeit with instances of short shot components due to the high thermal conductivity of the carbon fiber compared to glass fiber for which the prototype tool was designed for. 
The project demonstrated that recycled carbon fiber is a viable option in fiber reinforced compound, providing greatly increased strength and modulus for applications that require them. The "agglomerated" format that facilitated effective bulk solids transfer of recovered fiber showed promise for industrial application.

\section{INTRODUCTION}

Carbon fiber is an energy intensive material to manufacture and therefore has a significant embodied energy, more so than an equivalent mass of aluminum, steel, or glass fiber [1] [2]. As such, reusing carbon fiber manufacturing scrap that would otherwise go to landfill can greatly reduce the embodied energy of products manufactured from carbon fiber [3]. The focus of this project was repurposing carbon fiber manufacturing scrap into a discontinuous short-fiber thermoplastic composite that can be used for lightweighting applications in the automotive industry.

Composites are notoriously challenging to recycle due to the commingled nature of the materials [4] [5]. Notably, carbon fiber reinforced polymer (CFRP) sheets are composed of aligned long-fibers in a thermoset resin matrix. There are no known commercial methods to extract and maintain the alignment of these fibers, so alternative reuse strategies must be examined [6] [7]. A discontinuous fiber, while providing less directional strength than the aligned format, can still greatly enhance strength and stiffness relative to a neat plastic. Additionally, when integrated into a thermoplastic rather than thermoset matrix, the composite can potentially be ground and remolded for additional generations of products.

The technologies used for this project included chemical recycling at Vartega, Inc (Vartega, Golden CO) along with a process to densify and bind discontinuous fiber to facilitate improved bulk solids transfer versus loose fiber. Mature technologies, that is thermoplastic compounding and injection molding, were featured prominently at multiple scales to contextualize the performance of the discontinuous recycled carbon fiber thermoplastic (DRCFTP) composite.

Given low bulk density, high stiffness, high aspect ratio and high friability, chopped or milled fiber has been known to be difficult to feed into compounding systems. The agglomerated format tested in this project had previously received positive feedback on handling and performance from Vartega compounding partners, so was leveraged to produce a format that would be readily compatible with the larger compounders/feeders used for the later stages of the project. While the agglomerate format was applied only to chemically recycled and oversized-dry fiber in this project, the formatting process may be adaptable to fibers recycled through other (pyrolysis, thermolysis, solvolysis, hydrolysis, etc.) technologies.

The target industry for DRCFTP material is the automotive industry, which has the scale to consume a large volume of recycled material and is price-sensitive. While the layup process used for traditional CFRP is prohibitively time and labor intensive for medium to large production runs, plastic injection molding has long been a mainstay of the industry. In addition, lightweighting can provide significant value in the form of fuel savings. For lightweighting, a "pound is a pound" whether in an injection molded dashboard or a structural component.

\section{BACKGROUND}

Recycling for carbon composites is performed with either pyrolysis, which burns off resin under controlled conditions, or chemical approaches, which encompass a wide range of technologies such as solvolysis or hydrolysis. While technology does exist to recover these materials, discontinuous recycled fibers necessitate different manufacturing processes than those required for the continuous tows or aligned sheets typical of virgin fiber [6] [7]. 
This project aimed to close this sustainability gap by identifying benefits and challenges when using recycled or recovered carbon fiber manufacturing scrap as a reinforcing additive in thermoplastic compounding. To demonstrate whether this is a viable application, it must be shown that:

1. The fibers maintain comparable properties to virgin fibers after recycling

2. The fibers can be post-processed to allow for manufacturability, that is, the material can consistently be fed through commercially available standard compounding extrusion equipment

3. The compound provides valuable mechanical properties

4. The compound can successfully be injection molded into commercial parts

The general composition, microstructure, and phase property parameters that govern final composite mechanical performance are known from theoretical fiber mechanics. For example, a standard rule of mixtures estimate (i.e., Voigt estimate) was modified by Krenchel to yield the following relation [8] for composite Young's modulus

$$
E_{c}=\eta_{\theta} \eta_{L E} V_{f} E_{f}+V_{m} E_{m}
$$

where $E_{c}$ is the estimated composite tensile modulus, $\eta_{\theta}$ is a fiber orientation factor accounting for misalignment of fiber with the direction of applied load, $\eta_{L E}$ is a fiber length factor accounting for reduced reinforcement efficiency in a discontinuous fiber composite, $V_{f}$ and $V_{m}$ are the volume fractions of fiber and matrix phases respectively, and $E_{f}$ and $E_{m}$ are the Young's moduli of the constituent fiber and matrix phases respectively. Similarly, work by Kelly and Tyson concluded in a composite reinforced with aligned fibers below a critical length $l_{c}$ the following relation [9] for composite strength

$$
\sigma_{c}=V_{f}\left(l \tau_{c} / d\right)+V_{m} \sigma_{m}^{\prime}
$$

where $\sigma_{c}$ is estimated composite tensile strength, $l$ is fiber length, $\tau_{c}$ is the lesser of fiber-matrix interface strength or matrix shear strength, $d$ is fiber diameter, and $\sigma_{m}^{\prime}$ is matrix stress at composite failure. Critical length $l_{c}$ is the threshold above which composite failure occurs through fiber fracture while below which composite failure occurs through fiber pullout [10] [11] [12] [13] [14]. For the case of an extruded composite, fiber lengths will be well below the critical length from the high shearing action of the screw(s). From Eqs. 1 and 2, one can see that the core variables needing to be matched in an rCF composite to achieve vCF performance are: preserving fiber mechanical properties and aspect ratio through recycling and compounding, preserving relative fiber/matrix volume fractions (including void content), reapplying commercial sizing to the rCF surface ensuring comparable fiber-matrix interface strength, and achieving the same degree of relative fiber alignment during injection molding. As such, each of these factors was investigated and compared between BASF's commercial A3WC8 vCF based composite and the project produced rCF equivalent.

Single fiber testing was performed on recycled material to validate fiber integrity. Mechanical test specimens were formed and tested from recycled and virgin materials to benchmark material capabilities, while XCT and SEM were leveraged to compare fiber distribution. Handling characteristics of the postprocessed fiber were evaluated while compounding with commercial-scale equipment. Large complex parts were molded to contextualize performance of this material in a commercial context. The project was gated from an initial mechanical evaluation of lab-scale compounded recycled fiber (GNG 6.20.1) to commercial-scale compounding and injection molding of oversized agglomerates using the same product form as evaluated in the earlier stage and mechanical testing of the same (GNG 6.20.2 \& GNG 6.20.3). 
Given the expertise required in recycling, compounding, injection molding, non-destructive examination, and mechanical testing, a broad coalition of partners was assembled to contribute to this project.

- Colorado School of Mines-Performed analytical work

- IACMI-Assisted in project planning, partner coordination, and budget administration

- Michelman-Provided sizing for the project, performed micro-compounding, and analysis

- Oakridge National Laboratory_-Provided expertise and performed analytical work

- $\mathrm{SuRF} / \mathrm{MSU}$ - Coordinated prototype part injection molding

- UDRI-Performed small-scale prototype part molding and test specimen mechanical evaluation

- Vartega-Provided and formatted fiber used in this project, and administered the project

While not included on the project agreement as project partners, BASF provided resin, benchmark composite material, $40 \mathrm{~mm}$ compounding, test specimen injection molding, and guidance with full-scale molding. Similarly, Ford provided technical and commercial guidance with respect to performance specifications and target applications.

\section{RESULTS AND DISCUSSION}

\section{Task and Results Summary}

In accordance with the project agreement statement of work, milestones and GNGs were as follows:

1. 6.20.2.1 Creation of $10 \mathrm{~kg}$ sample of recovered carbon fibers, cut to nominal $6 \mathrm{~mm}$ length

2. 6.20.3.1 Deliver $10 \mathrm{~kg}$ of recycled sized fiber delivered for compounding trials

3. 6.20.4.3 Final decision on tooling for small-scale prototype components

4. 6.20.4.1 Thirty test specimens at lab-scale molded

5. GNG 6.20.1 Validation of injection molded prototype test specimens $\geq 80 \%$ of specifications (tensile strength, impact strength, tensile modulus)

6. 6.20.2.3 Creation of $100 \mathrm{~kg}$ sample of recovered carbon fibers, cut to nominal $6 \mathrm{~mm}$ length

7. 6.20.3.2 Deliver $100 \mathrm{~kg}$ of recycled sized fiber delivered for compounding

8. GNG 6.20.2 Validation of functional demonstration part (1 kg mass) with mechanical properties of intermediate-scale Ford injection molded parts $\geq 80 \%$ of specifications (tensile strength, impact strength, tensile modulus)

9. 6.20.2.3 Creation of $300 \mathrm{~kg}$ sample of recovered carbon fibers, cut to nominal $6 \mathrm{~mm}$ length

10. 6.20.3.3 Deliver $300 \mathrm{~kg}$ of recycled sized fiber delivered for compounding

11. 6.20.4.4 Final decision on tooling for intermediate and commercial-scale prototype components

12. 6.20.4.2 Functional commercial-scale demonstration part $(2 \mathrm{~kg})$ produced

13. GNG 6.20.3 Mechanical properties of large-scale Ford injection molded parts $\geq 90 \%$ of specifications (tensile strength, impact strength, tensile modulus)

14. 6.20.5.1 Brief characterization plan and methods to DOE

15. 6.20.5.2 Final project report assembled, approved by team, and provided to IACMI

Items 1-5 can be grouped as "Task 1" (small-compounder testing), Items 6-8 grouped as "Task 2" (intermediate-compounder testing), and Items 9-13 as "Task 3" (large-compounder testing).

The execution plan for these milestones shifted through the duration of project performance, notably:

1. Michelman's expertise dealt with the sizing of continuous fiber. As such, scope for sizing the discontinuous fibers was shifted to Vartega $(6.20 .3 .1,6.20 .3 .2,6.20 .3 .3)$

2. Given the need to develop robust mechanical data during Task 1, coupled with insufficient alternative low-volume tools, the parts for the small-scale tests were test specimens (6.20.4.3) 
3. The Ford standard was written for ISO 527-2 Type 1A tensile and ISO 197-2 Type D impact mechanical test specimens. For Task 1, however, ISO 527-2 Type 5A tensile and ASTM D6110 impact specimens were used instead to generate a robust sample set (tensile specimens) and utilize available tooling (impact specimens). To provide a like-for-like evaluation, baseline commercial material was molded and tested using the same tools. (6.20.4.1 and GNG 6.20.1)

4. While the Task 1 fibers were recovered from prepreg using Vartega chemical recycling processes, Task 2 and 3 fibers were generated from oversized dry scrap material post-processed in a manner similar to that of the Task 1 material. $(6.20 .2 .3,6.20 .2 .4)$

5. For Tasks 2 and 3, ISO test specimen mechanical characterization was performed by UDRI (GNG 6.20.2, GNG 6.20.3).

6. GNG 6.20.2 and 6.20.3 include ambiguous language implying measurement of mechanical properties using prototype (complex) parts. However, cutting a sample from a seatback for mechanical testing was deemed impractical, as any such coupon would not be compliant (e.g., appropriate/consistent thickness) with a standard ISO or ASTM testing method and would vary from location to location given nonuniformities of moldflow. SuRF's experience is that samples machined from molded parts usually result in lower mechanical properties as compared to molded test coupons. Hence, to confirm mechanicals, standard mechanical test specimens were molded from the Task 2 and 3 materials and tested. Satisfactory results from these tests were the basis for continued pursuit of longer-lead prototype seatback part molding. (GNG 6.20.2, GNG 6.20.3)

7. Given the SuRF (and other) facility shutdowns due to COVID-19 and facility/tooling upgrades, limited windows were available for molding at SuRF for this project. As such, project work for Task 2 and Task 3 were combined. Similarly, Task 2 compounding was performed by a thirdparty. (6.20.4.2)

8. There were significant delays in the final prototype molding portion of the project due to COVID-19 logistical delays along with tooling manufacturing defects. While the project was extended to allow for these delays, the final prototype part molding was performed at the tooling manufacturer's site under the combined on-site supervision of the tooling manufacturer, SuRF, and BASF. (6.20.4.2)

9. Only Task 3 material was used for the prototype seatback molding. This material was available in sufficient volumes to allow for the losses incurred by the high rate of short shots experienced with the tooling (6.20.4.2).

10. Optional subtasks involving SMC were not performed due to schedule and budget constraints.

Task 1 milestones were intended to provide thorough characterization of a short, recycled carbon fiber thermoplastic compound, quantifying how well it performs against a commercially available baseline. This task was successful in showing similar performance and much improved (strength and modulus) properties relative to the neat plastic. From a performance perspective, recycled carbon fiber is wellsuited for compounding applications. During the execution of this work, Dragonfly ORS was found to be effective at quantifying fiber distribution in compounded test specimens, which may prove to be a useful technique in other studies evaluating more complex geometries.

Task 2 and Task 3 milestones were intended to evaluate transition from lab conditions to practical commercial application. Of primary interest were ease of feeding, consistency of molding, and implementation into a complex geometry. Both the intermediate-scale (third-party operator) and commercial-scale (BASF) compounding validated that the agglomerate product-form fed through commercially available loss-in-weight (LIW) gravimetric feeders effectively. Both operators faced challenges with material surge when compounding neared $40 \%$ carbon fiber weight fill, but operating parameters were adjusted until the issues resolved. Resulting Task 3 material properties exceeded Ford specification targets and approached those of the BASF baseline specification. However, Task 2 material, using standard modulus fiber, did not meet Ford specification requirements. When injection molded into a 
seatback prototype part, the Task 3 material was able to create functional parts. However, the tooling hot runner system was unable to adequately compensate for the relatively high thermal conductivity of highfill carbon fiber relative to the $50 \%$ fiberglass material for which it was designed/tested, resulting in material freezing and a high-percentage of short shots. While this challenge limited the number of functional parts that could be created with the supplied material, SuRF is confident that the material would create consistent functional parts if the hot runner system was suitably modified.

\section{Task 1 [Micro- and small-scale compounding]}

\section{Recycling}

Expired epoxy prepreg scrap was chemically treated to separate the resins and fibers through dissolution. The recycled carbon fiber was extracted from the prepreg matrix through immersion in solvent, followed by a secondary immersion in liquid carbon dioxide $\left(\mathrm{CO}_{2}\right)$ to recover the process chemistry. The process to obtain the recycled carbon fibers followed the procedure defined in US Patent 10487191B2 [15]. The material processed was Toray intermediate modulus T800S fiber, generating approximately $10 \mathrm{~kg}$ of dry fiber for compounding at the University of Dayton Research Institute (UDRI; Dayton, OH) and microcompounding at Michelman, Inc (Michelman; Cincinnati, OH). Prepreg feedstock and post-recycled dry fiber are presented in Figure 1.

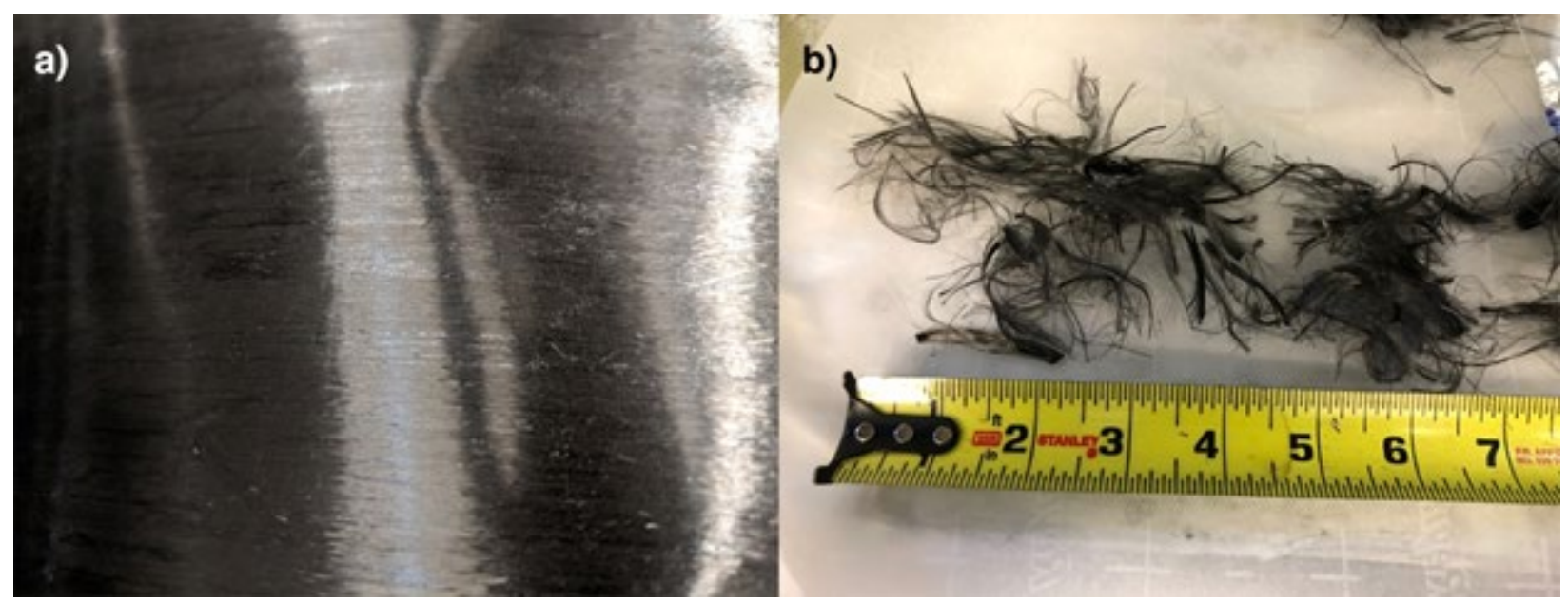

Figure 1: (a) Prepreg before recycling and (b) dry fiber after recycling

The resulting dry fibers were randomly oriented with a high aspect ratio. If fed through a hopper, this material will bridge (rigidly interlock), making this recycled product unsuitable for thermoplastic compounding applications. To resolve material flow challenges, Vartega applied a process wherein the fibers were size-reduced and then bound into agglomerates. These particles include a sizing (notably Hydrosize U201) that would potentially improve adhesion with a thermoplastic matrix (polyamide 66) while also reducing release of particulate from the friable fibers during handling. This material was sent to UDRI and Michelman for further processing.

\section{Single Fiber Testing}

To ascertain any impact of the recycling process on inherent fiber properties, dry, recycled T800S fiber, recovered from prepreg by Vartega was compared against virgin T800S carbon fiber from Toray Composite Materials American, Inc. (Tacoma, WA). Individual filament tensile properties of virgin and rCF T800S were measured using a Textechno H. Stein GmbH \& Co. KG Favimat+ fiber tester (Mönchengladbach, North Rhine-Westphalia, Germany) based on ASTM C1557 [16]. 
Filament density measurements indicate that the true volumetric density of the rCF specimens was $1.1 \%$ lower than the tested vCF (Figure 2a). Conversely, linear density was observed to be $3.5 \%$ higher in the rCF specimens than the tested vCF (Figure 2b). The data in Figure 2c indicates a 2.4\% increase in mean fiber diameter of recycled fibers, which was found to be statistically significant, as the difference was larger than one standard error. To obtain the magnitude of error for the fiber strength when using the fiber diameter, a Monte Carlo analysis can be applied, and is detailed in Appendix X1 of ASTM C1557 [16]. The exact reason for the measured change in diameter and density of the rCF compared to vCF is unknown. It is possible that differences in humidity, temperature, and machine calibration could all have affected the measured diameter and fiber density apart from the recycling process. More testing would be required to discover whether it is the recycling process or other variables and assumptions that caused the difference in measured values.

Analysis of tensile tests performed on individual carbon fiber filaments indicate a 3\% decline in Young's modulus (Figure $2 \mathrm{~d})$ for the $\mathrm{rCF}(\mathrm{n}=18)$ versus $\mathrm{vCF}(\mathrm{n}=19)$ samples, which is consistent with the slightly smaller volumetric density (Figure 2a). Also note that Toray tests long strands of cured resin impregnated tows containing tens of thousands of filaments to generate the data used in the manufacturer data sheet [17], and so the data reported here for single fibers are different. However, the individual filament testing method used here is expected to be more representative of fiber performance in the target compounded thermoplastic as the shearing action of the extrusion line and molding processes will result in extremely short, highly filamented fiber being dispersed throughout the matrix. Also, the observed single fiber stiffness is consistent with other reports of single fibers [18] [19] and the rCFs are within the expected failure values.

Small decreasing trends in mean tensile strength (Figure 2e) and tensile strain (Figure 2f) were also observed, though they were differentiated by less than one standard error, hence not statistically significant. Altogether, this data indicates that the carbon fiber mechanical and density properties are relatively unaffected by recycling. Therefore, the input $\mathrm{rCF}$ should be able, in principle, to provide the same level of mechanical reinforcement as discontinuous vCF. 

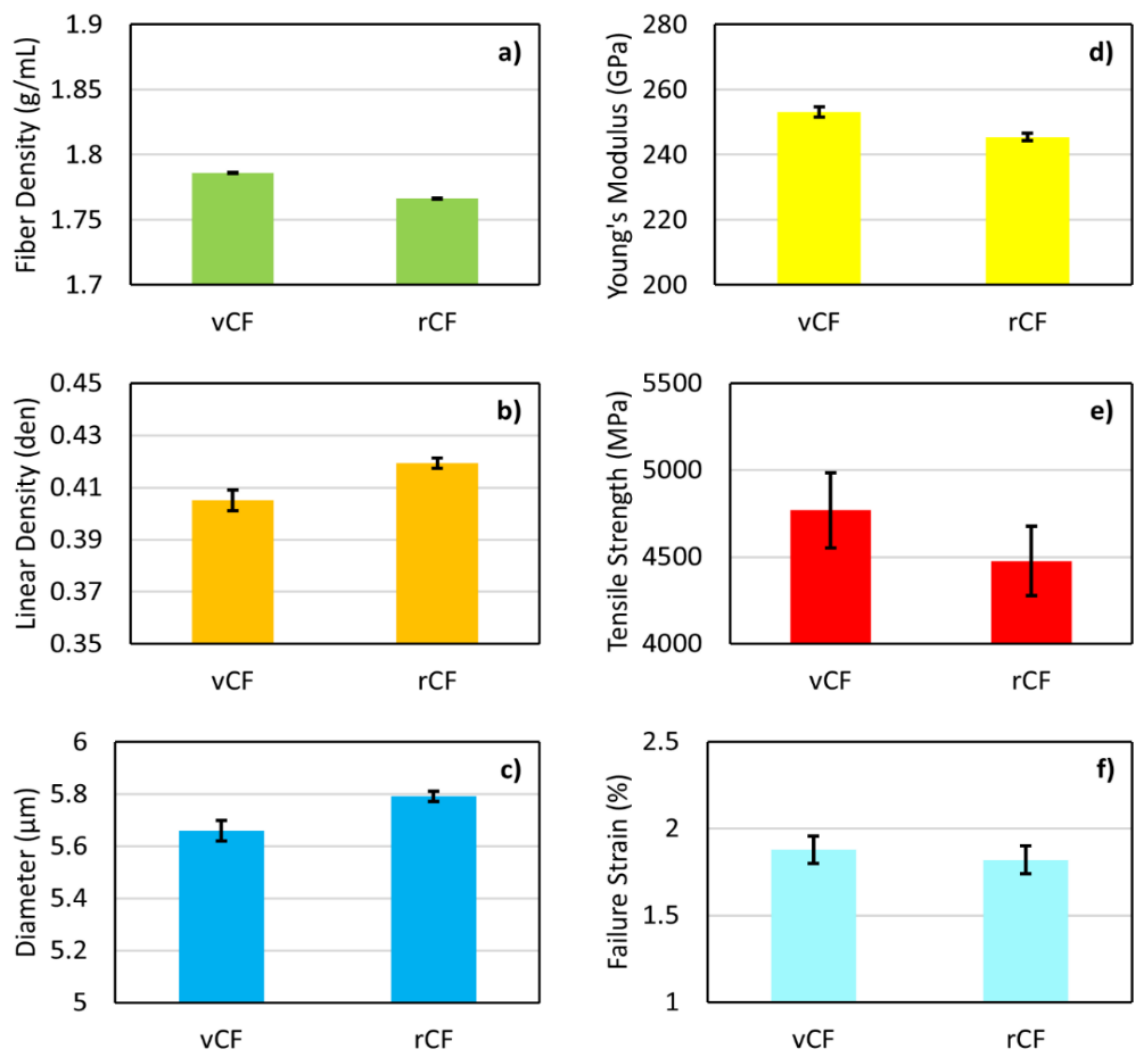

Figure 2: Measured average CF filament densities (a-true volumetric, b-approximate linear), calculated average diameters (assuming cylindrical fiber geometry), and tensile properties with error bars denoting standard error. For vCF, $\mathrm{n}=19$. For $\mathrm{rCF}, \mathrm{n}=18$.

\section{Surface Characterization}

XPS was used to confirm whether the sizing agents applied by Michelman to the project rCF successfully created new functional groups on the fiber surface. For all the tested samples, carbon, oxygen, and nitrogen peaks were observed as well as elementary ratio changes after different sizing applications. A noticeable amount of calcium, which measurements indicate originated with the sizing, was observed for all three sized fiber types. The changes in the surface element composition confirmed the sizing was successfully applied.

The chemical functional groups on the fiber samples were further analyzed through deconvoluting $\mathrm{C} 1 \mathrm{~s}$ spectra. The sizing did not change the chemical functional groups on the surface; however, the ratio of these functional groups changed significantly. These changes in surface functional groups would also be expected to affect the interfacial interactions, such as hydrogen bonds, between the carbon fiber and PA66 matrix when used in reinforced composites.

\section{Micro-compounding}

Prior to lab-scale compounding, three sizing agents were screened for mechanical performance via microcompounding/injection molding. This process used an R\&D compounder and molder that are well-below typical industrial-scale to create 7-8 low mass mechanical samples for each evaluated sizing. In these early trials, the U501-sized intermediate modulus rCF/PA66 composite exhibited a minorly elevated flexural strength and modulus compared with the other sized and unsized composites, suggesting slightly enhanced fiber-matrix interfacial adhesion. Besides an improvement in the flexural properties, the impact and tensile properties of the U501 intermediate modulus $\mathrm{rCF} / \mathrm{PA} 66$ also indicated a minor increase in 
performance over the other IM rCF/PA66 composites. Supplementary testing on some standard modulus fiber did show substantial mechanical property improvements when using U201 sizing, however the difference in composite mechanical properties between the different sizing agents for the intermediate modulus fiber was insignificant from a practical perspective, so U201 was selected by Vartega to size the rCF used for lab-scale composite compounding.

Notably, while sizing performance was originally intended to be evaluated through single fiber pullout as performed by Michelman for other resin systems, these tests failed to produce consistent results for the project's PA66, so micro-compounding was performed instead. Additional investigation indicated that the single fiber testing crucible required ozone treatment to match the surface energy of the matrix and thereby avoid subsequent test failure. However, fiber pullout testing was not repeated given the shift to micro-compounding.

\section{Compounding and Molding}

PA66 (Ultramid A27 EZ 08) from BASF and rCF from Vartega were compounded and extruded into multiple strands in a co-rotating, twin-screw Coperion ZSK 26 with $25 \mathrm{~mm}$ barrels and then pelletized into pellets approximately $4 \mathrm{~mm}$ long. Compounding to the targeted $40 \mathrm{wt} \%$ fiber loading presented a significant challenge with the existing lab-scale equipment. To avoid fiber/polymer feeding issues and overburdening the smaller extruder, compounding was shifted to a two-step approach that involved first compounding PA66 and $\mathrm{rCF}$ to $25 \mathrm{wt} \%$ followed by compounding the material from the first run with additional rCF to approach $40 \mathrm{wt} \%$. Small batches of about $100 \mathrm{~g}$ were initially mixed at the desired ratios, loaded directly onto the screws of the extruder, and pushed using a wooden block to ensure the entire mixture was pulled into the extruder. Although the extruder had to be run at a very slow rate to accommodate the solid material inputs without over-torquing the machine, the resulting $\mathrm{rCF} / \mathrm{PA} 66$ compound was able to reach an acceptable $37.62 \mathrm{wt} \%$ fiber loading. Samples were also compounded at lower fiber loadings of $9.95 \mathrm{wt} \%, 12.19 \mathrm{wt} \%$, and $26.42 \mathrm{wt} \%$ to assess impact on composite tensile performance.

A lab-scale Simplomatic Manufacturing Co. Pro.63 was used to injection mold ISO 527-2 [20] type 5A tensile specimens from both the commercial BASF A3WC8 material and experimental material, hereafter referred to as HBF-37. As no built-in tool heating was present in the system, heat guns were placed in strategic areas around the mold. An IR thermometer was used throughout the molding process to ensure even heating of the tool and control the process. Vents were cut into the tool to overcome issues with backpressure.

Tensile testing was conducted on the fabricated specimens using an Instron model 5984 load frame equipped with a $150 \mathrm{kN}$ load cell. The Pro. 63 injection molding machine provided insufficient pressure to mold the thicker impact testing samples. Thus, a Dr. Boy GmbH \& Co. KG BOY 35 EVV injection molder (Neustadt-Fernthal, Rhineland-Palatinate, Germany) was used to produce ASTM D6110 [21] impact test specimen blanks. Impact specimen notches were machined after molding.

\section{Mechanical Testing}

There was found to be a linear correlation between increased fiber loading and higher composite tensile properties over the tested range. The mechanical test results of the compounded HBF-37 experimental composite were further compared to the injection molded baseline specimens made with BASF's commercial A3WC8 product, the BASF technical data sheet values for A3WC8, and Ford Motor Company's Engineering Material Specification WRS-M4D1062-A1 for heat stabilized 40\% short carbon fiber filled PA66. From Table 1, the HBF-37 composite exceeds the mechanical performance requirements of the Ford specification. The Ford standard was written for ISO 527-2 Type 1A tensile and ISO 197-2 Type D impact mechanical test specimens as opposed to the ISO 527-2 Type 5A tensile and 
ASTM D6110 impact specimens used in this study for both the BASF A3WC8 and HBF-37 composites. However, it is unlikely that the HBF-37 composite's properties would fall below those of the standard given the close match in measured mechanical properties to those of the commercial BASF A3WC8 (baseline) composite test specimens. The comparable tensile and impact properties between the BASF A3WC8 and the HBF-37 samples also suggests that any additional resin degradation that may have occurred from the two-cycle compounding process used to fabricate HBF-37 was insufficient to alter final composite performance. Altogether, these results indicate that PA66 compounded with rCF can serve as a viable alternative to commercially available $\mathrm{vCF}$ materials that meet automotive OEM specifications. Note that the $37 \%$ percent fill strength and modulus are likely lower than those of a sample produced to the target of a true $40 \%$ fill. However, as the mechanicals were sufficient to meet project milestones, no additional compound optimization was performed.

Table 1: Mechanical property comparisons between compounded rCF and commercial material.

\begin{tabular}{l|c|c|c|c|c|c}
\hline \multirow{2}{*}{ Mechanical Property } & \multicolumn{2}{|c|}{ Specifications } & \multicolumn{2}{c|}{ Test Data (averages) $\dagger$} & \multicolumn{2}{c}{ Standard Deviation } \\
\cline { 2 - 7 } & BASF [22] & Ford [23] & $\begin{array}{c}\text { BASF } \\
\text { A3WC8 } \\
\text { (baseline) }\end{array}$ & $\begin{array}{c}\text { UDRI } \\
\text { HBF-37 }\end{array}$ & $\begin{array}{c}\text { BASF } \\
\text { A3WC8 } \\
\text { (baseline) }\end{array}$ & $\begin{array}{c}\text { UDRI } \\
\text { HBF-37 }\end{array}$ \\
\hline Tensile Strength (MPa) & 295 & 245 & 269 & 298 & 7.85 & 9.12 \\
Tensile Modulus (GPa) & 38.1 & 30 & 36.3 & 33.2 & 1.59 & 2.56 \\
Impact Strength [kJ/m²] & 11 & 6.5 & 9.57 & 8.39 & 0.446 & 0.399 \\
\hline
\end{tabular}

$\dagger$ Type 5A specimens used from ISO 527-2

Note that 6 specimens of each material were tested to determine impact properties and 7 specimens of each material were tested to determine tensile properties.

Fracture Surface Scanning Electron Microscopy Evaluation

To study the fracture surface of the tested tensile specimens, a TESCAN MIRA3 LMH Schottky field emission SEM was used. The injection molded tensile test specimens were also loaded into a Zeiss Xradia Versa 3D X-ray microscope to determine void content, fiber volume fraction (FVF), and fiber orientation. After scanning the samples, Dragonfly ORS was used to analyze the samples.

Scanning electron microscopy (SEM) imaging was conducted on the HBF-37 tested tensile samples to assess failure modes and fiber-matrix bonding. Figure 3 shows the failure surface of each of the samples. Images of the BASF baseline material in Figure $3 \mathrm{a}$ and Figure $3 \mathrm{~b}$ reveal the main mode of failure is fiber pullout through fiber-matrix interface failure. This failure mode is consistent with the short fiber lengths measured after compounding and molding, as such short fibers should be well-below the critical length threshold at which composite failure transitions from fiber fracture to fiber-matrix interface failure. The fibers also appear generally aligned perpendicular to the failure plane, indicating greater strength in the loading direction. This is to be expected as fibers will nominally align in the direction of material flow during the injection molding process. Two HBF-37 samples were imaged for comparison. Overall, the images are very similar to the BASF baseline material. Comparable fiber alignment and failure modes further support the assertion that the input $\mathrm{rCF}$ processed nearly identically to $\mathrm{vCF}$, allowing it to act as a more sustainable fiber replacement without altering composite failure behavior or directional reinforcement efficiency. 


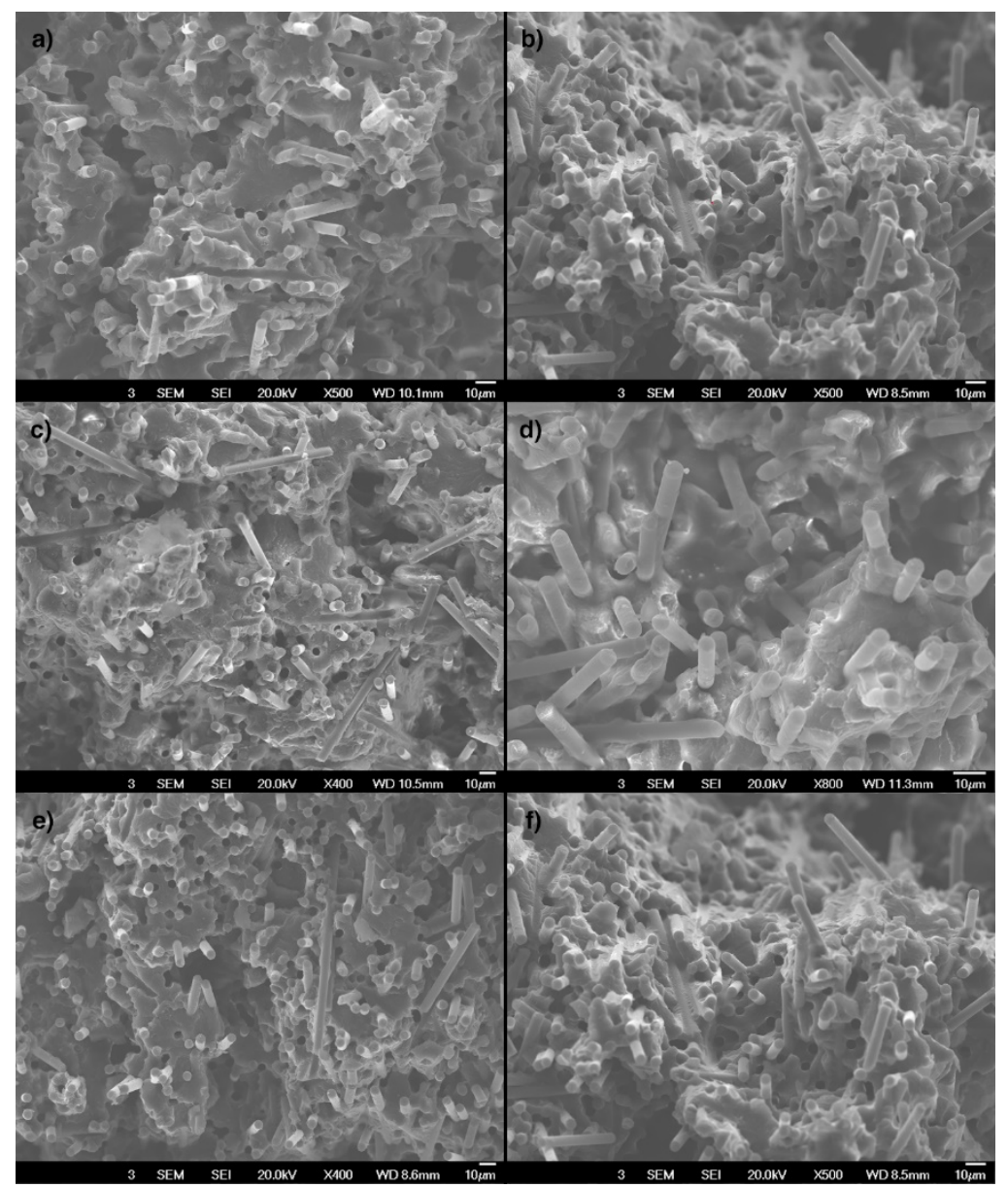

Figure 3: SEM images of (a, b) BASF vCF, (c, d) A-02 rCF, and (e, f) A-05 rCF fracture surfaces.

Fiber Dispersion

Fiber length distributions (FLDs) were measured after compounding BASF's commercial vCF-based A3WC8 composite and after compounding and pelletization of the study-produced $37.62 \mathrm{wt} \% \mathrm{rCF} / \mathrm{PA} 66$ composite (referred to as HBF-37), as well as after injection molding. FLD for each sample was manually measured using ImageJ with over 500 fibers measured for each sample condition.

According to Vartega's (rCF recycler) specifications, the nominal starting lengths of the rCF used for compounding was in the range of 6-10 $\mathrm{mm}$. On this basis, average fiber length declined by over $90 \%$ to $150 \mu \mathrm{m}( \pm 3.86 \mu \mathrm{m}, 1$ standard error, $\mathrm{n}=521)$ after lab-scale compounding and pelletization. This decline is an unsurprising result of the highly friable carbon fiber being broken down by the dynamic shearing forces present during compounding. Further processing via injection molding resulted in an additional $33 \%$ decline to $100 \mu \mathrm{m}( \pm 2.06 \mu \mathrm{m}, 1$ standard error, $\mathrm{n}=1699)$. This final FLD result proved very similar to BASF's commercial A3WC8 product post injection molding, average length $93 \mu \mathrm{m}( \pm 1.85 \mu \mathrm{m}, 1$ standard error, $\mathrm{n}=915)$, indicating the impact of FLD on $\mathrm{rCF}$ composite performance should be comparable to that for existing vCF material.

Three untested tensile specimens were used for XCT characterization: one commercial BASF material sample (A3WC8-BASF) and two identical HBF-37 samples (HBF-37_10 and HBF-37_14). XCT images were captured at the center of the gauge section within the ISO 527-2 Type 5A test specimens. The A3WC8-BASF sample exhibited a void content of $0.21 \mathrm{vol} \%$, which was comparable to the two tested 
rCF based specimens HBF-37_10 at 0.15 vol\% and HBF-37_14 at 0.13 vol\%. The slightly higher void content in the commercial sample may be tied to the higher overall fiber content, as more fiber means more interfaces and internal obstructions to resin and bubble flow. All voids in the samples were found to be concentrated in the center of the sample cross-sections (Figure 4).

a)

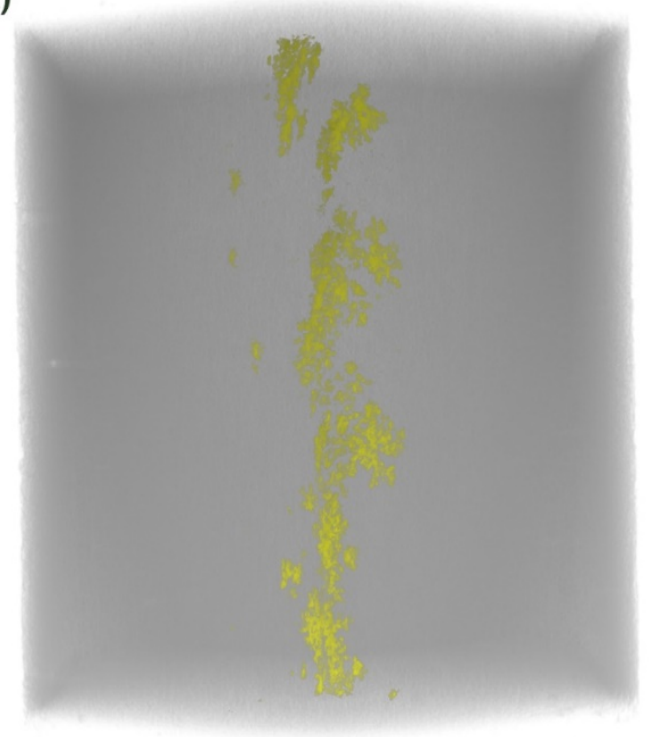

b)

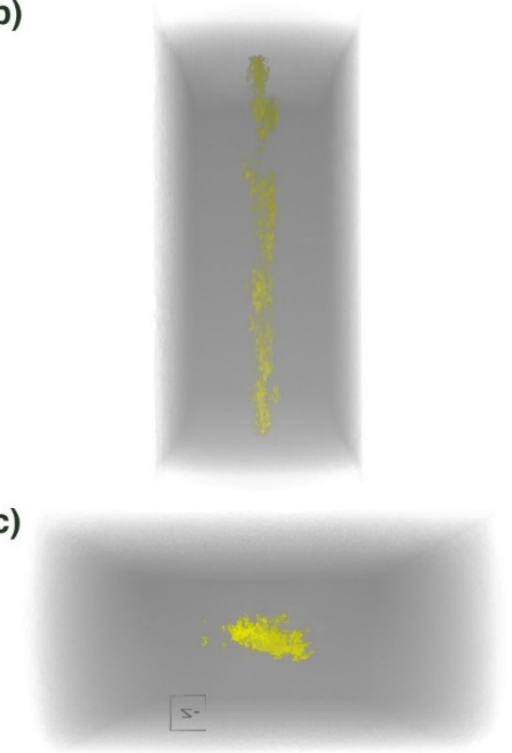

Figure 4: Voids detected by XCT in the rCF HBF-37_14 sample with (a) front, (b) side, and (c) top views.

To extract relevant fiber microstructural data from the XCT scans, the files were processed in Dragonfly ORS using a histogram equalization tool. The average XCT measured FVF $26.46 \mathrm{vol} \%$ for the vCF sample (Figure 5a) agrees to within a few percent of the 29.59 vol\% FVF estimated from the $39.9 \mathrm{wt} \%$ obtained during acid digestion. The FVF measurements of the rCF specimens came in slightly lower at $22.30 \mathrm{vol} \%$ and $21.21 \mathrm{vol} \%$ (Figure $5 \mathrm{~b}$ and Figure $5 \mathrm{c}$ ), as would be expected from the lower $37.62 \mathrm{wt} \%$ loading of the HBF-37 composite but were still relatively close both to the $27.86 \mathrm{vol} \%$ estimated from weight fraction measurement and to the loading of the fiber loading of the commercial BASF composite being compared against. As such, fiber loading and composite void content would not be expected to cause any large deviation in mechanical performance between the $\mathrm{vCF}$ and $\mathrm{rCF}$ parts. This microstructure governs the experimentally measured composite mechanical behavior and thus its importance to the composite analysis. However, global tensile specimen structure may vary such as higher porosity and lower fiber alignment in the wider grip sections. Effects of injection mold tooling geometries on final composite microstructures are, however, beyond the scope of this study.

Though fractography qualitatively indicated similar fiber alignment along the injection flow (i.e., tensile test) direction in both vCF and $\mathrm{rCF}$ composites, XCT data was used to quantify and compare the exact alignment distributions of fibers in the material flow direction. The vCF sample in Figure $5 \mathrm{~d}$ had the closest average alignment at $7.31^{\circ}$ off angle to the axis of the tensile test direction. One of the two rCF samples (Figure 5e) similarly had a $10.00^{\circ}$ off angle and similar spread in fiber orientation distribution. The second $\mathrm{rCF}$ sample in Figure $5 \mathrm{f}$ exhibited a much larger average off angle at $27.39^{\circ}$. Further analysis of the XCT data showed that this mean was biased by misalignment of fibers at the sample edges.

Comparison of the mode of each sample reduces the effect of the edge fiber misalignment bias; the $2.75^{\circ}$ of the $\mathrm{vCF}$ sample compares well with the $2.50^{\circ}$ and $5.00^{\circ} \mathrm{rCF}$ values. Overall, reinforcement efficiency 
from fiber orientation is similar between the $\mathrm{vCF}$ and $\mathrm{rCF}$ materials despite higher variation in the $\mathrm{rCF}$ composites (Figure 5).
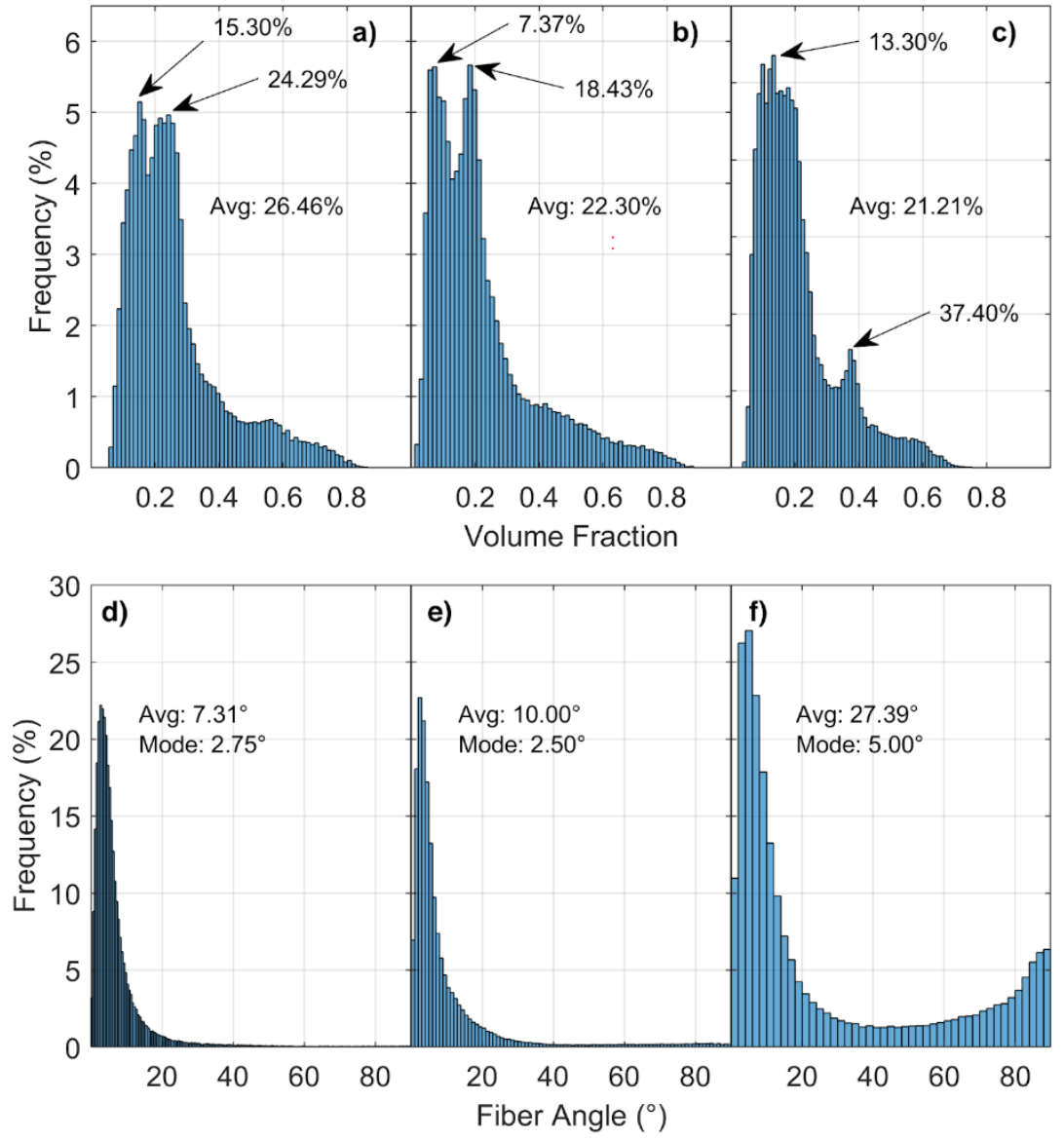

Figure 5: FVF and angular orientation measurements of (a, d) A3WC8-BASF, (b, e) HBF-37_10, and (c, f) HBF-37_14 samples, respectively, from XCT image analysis.

\section{Task $2 \& 3$, Creation of commercial parts}

\section{Material Production}

With mechanical properties identified during Task 1, Tasks 2 and 3 focused on product form and application in practical geometry. Dry (not from prepreg) material was oversized into similar agglomerates as were produced for Task 1 by Vartega. The Task 1 fibers and Task $2 \& 3$ fibers all processed into similar agglomerates using the same processing equipment. However, during the time between production of the Task 1 and Task 2 process material, Vartega refined their processing techniques to improve flowability of the material and efficiency of the conversion process. The Task 2 and 3 efforts demonstrated the ability to produce consistent agglomerates at commercial scale with both standard and intermediate modulus fiber types. Given the reduced availability of SuRF equipment due to COVID-19 and tooling supplier issues, Task 2 material (standard modulus) was compounded (27 mm) by a third-party and injection molded into test specimens. While prototype part molding had been anticipated to be performed at SuRF, vendor tooling delays required molding to be performed at the tooling vendor's facility under the supervision of SuRF and BASF personnel.

Task 3 material (intermediate modulus) was compounded at BASF (40 mm) and injection molded using the SuRF seatback tool (Figure 6). The tool was a seat component also used for IACMI project 3.9. This 
tool was a dual cavity design with complex molded features including ribs, clips, and attachment holes. The tool included 14 sequential valve gates along with hot runners, hot drops, and cooled tips.

Task 3 material was run, as it had the highest available volume. During molding, it was found that the tool was generating a large percentage of short shot parts. Notably, the material would freeze at the gates, resulting in alternating functional molding results between the pan and seatback portions of the tool. While the tooling was verified before purchase with 50\% glass / 50\% PA6 composite and consistently produced parts for project 3.9, this verification only addressed the mechanical flow of high-filled glass fiber composite materials. The higher thermal conductivity of carbon relative to glass resulted in unexpected freezing issues in the cooled portions of the drops. To achieve even inconsistent molding, the operators adjusted the injection temperatures from $288^{\circ} \mathrm{C}$ to $343^{\circ} \mathrm{C}$ - near the maximum allowable for PA66. While molding trial results were mixed, those parts that did mold were determined to have very good surface finish for $40 \%$ fill material. While not tested, it is presumed that the BASF baseline material would experience similar issues due to the same mechanism when using this tool. SuRF anticipates that the tool would consistently produce parts with either material if the hot runner system were modified to eliminate freezing in the drops. Due to the limited Task 2 material coupled with the inconsistent tool performance, no Task 2 material was molded into parts. 7 parts were molded with the Task 3 material as shown in Figure 7, Figure 8, and Figure 9.

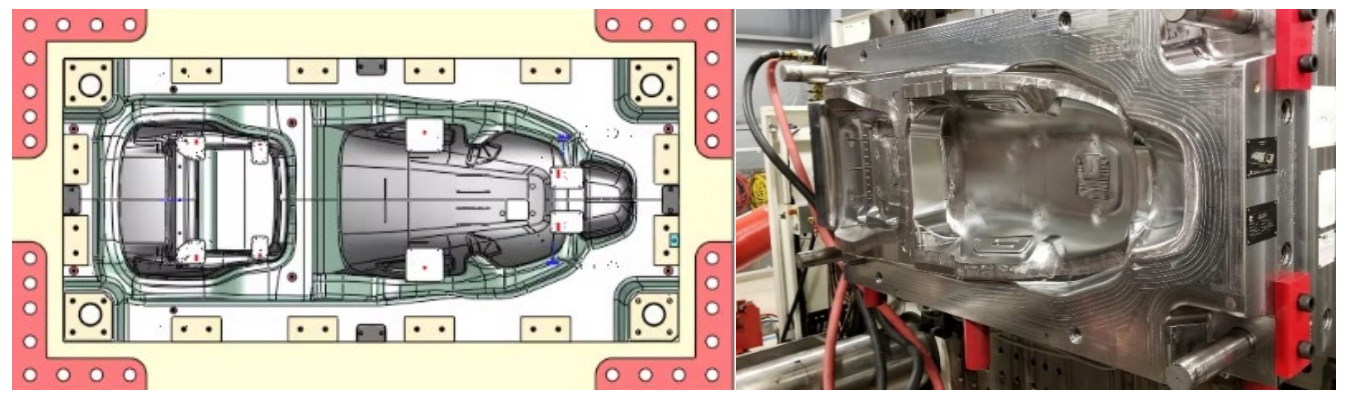

Figure 6: Seat component tool used for project 6.20

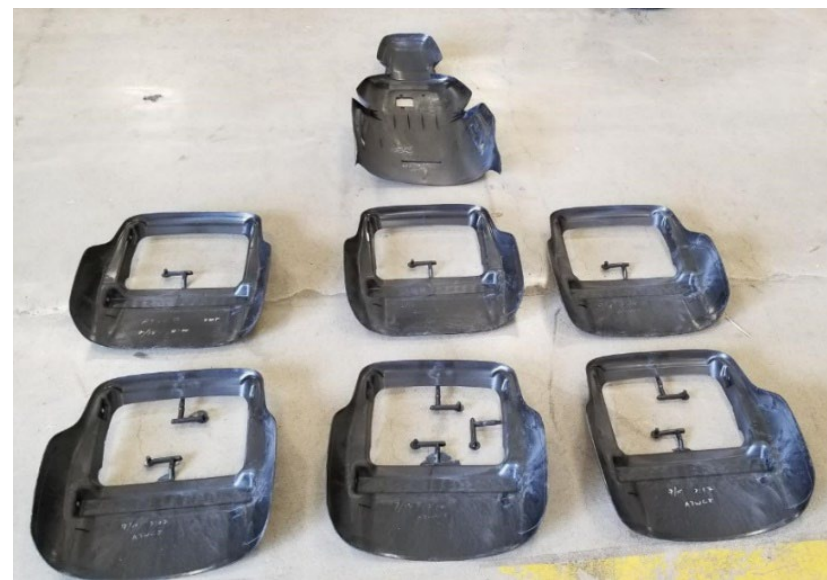

Figure 7: Fully filled components molded from Task 3 material 


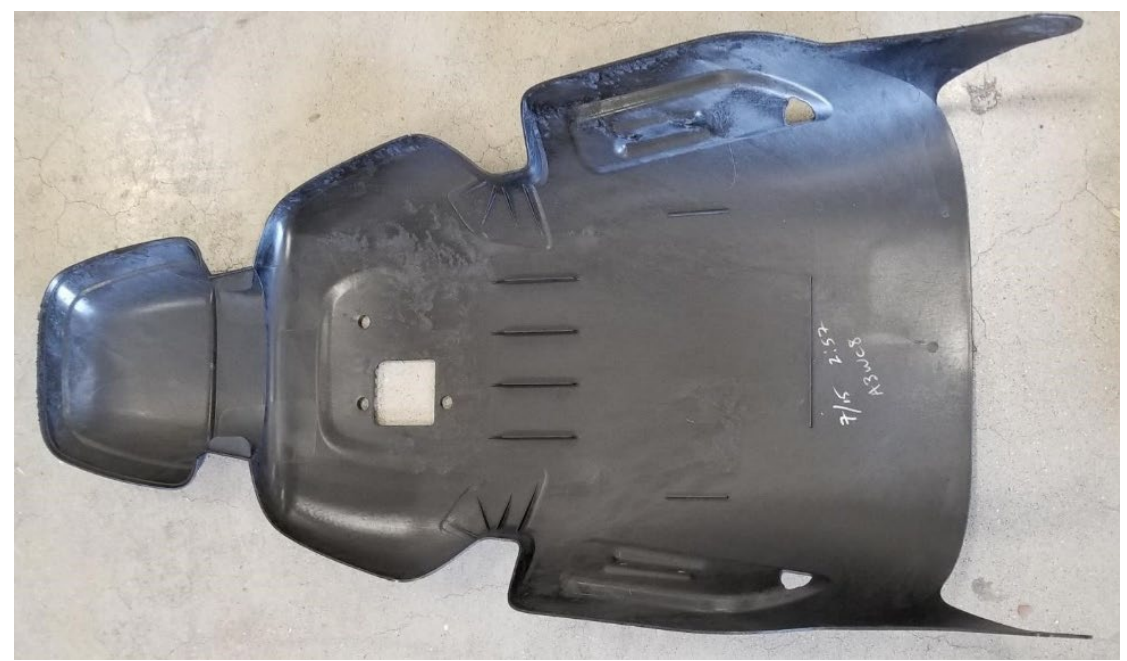

Figure 8: Detail of fully molded seatback

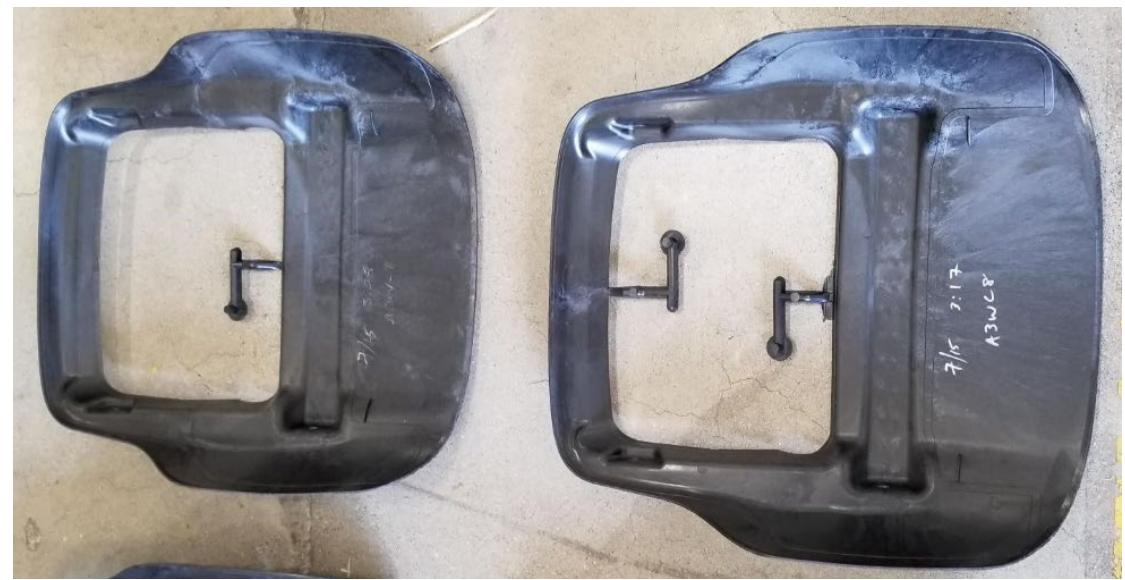

Figure 9: Detail of fully molded Pans

Mechanical Test Results

BASF molded mechanical test specimens to their datasheet ISO specifications that were then tested by UDRI. For both Task 2 and Task 3, 20 tensile and 40 flex specimens were molded of the respective compound by BASF, with UDRI machining the notches in the flex specimens for impact testing. Unlike Task 1, these tests used the ISO 527-2 Type 1A tensile and ISO 197-2 Type D impact mechanical test specimens referenced in the Ford specification.

Table 2: Mechanical property results for Task 2 and Task 3 material

\begin{tabular}{l|c|c|c|c|c|c}
\hline \multirow{2}{*}{ Mechanical Property } & \multicolumn{2}{|c|}{ Specifications } & \multicolumn{2}{c|}{ Test Data (averages) $\dagger$} & \multicolumn{2}{c}{ Standard Deviation } \\
\cline { 2 - 7 } & BASF [22] & Ford [23] & Task 2 mat'l & Task 3 mat'l & Task 2 mat'l & Task 3 mat'l \\
\hline Tensile Strength (MPa) & 295 & 245 & 220 & 309 & 4.96 & 8.68 \\
Tensile Modulus (GPa) & 38.1 & 30 & 29.2 & 35.3 & 2.464 & 2.132 \\
Impact Strength [kJ/m²] & 11 & 6.5 & 6.52 & 12.3 & 0.166 & 0.642 \\
\hline
\end{tabular}

$\dagger$ ISO 527-2 Type 1A tensile and ISO 197-2 Type D impact specimens used 
As apparent from Table 2, the Task 2 standard modulus fiber composite specimens showed reduced strength, modulus, and impact strength relative to the Task 3 intermediate modulus fiber composite specimens. This is unsurprising given the increased mechanical properties of intermediate relative to standard modulus fibers, along with the increased surface area per unit mass of the intermediate relative to standard modulus fibers.

Task 3 mechanicals exceeded the target properties of the Ford specification, while the Task 2 mechanicals underperformed targets. While Task 3 mechanicals met the more rigorous tensile strength and impact strength standards of the BASF (baseline) material specification, the tensile modulus was relatively reduced. This incongruity may result from differences in processing, testing, or baseline fiber properties, but identifying the root cause is beyond the scope of work performed for this project.

Task 1 data (Table 1) is not directly comparable to Task 2 and 3 mechanicals (Table 2), as the tests used different tensile specimen geometry. However, Task 3 and Task 1 showed similar trends of exhibiting comparable strength but slightly reduced modulus relative to the specification/baseline.

\section{BENEFITS ASSESSMENT}

Recycling carbon fiber composites can provide substantial benefits, including reduced costs (compared to virgin materials), reduction of waste [24], and reduction of greenhouse gases from the energy-intensive manufacturing process. Further, commercial integration of such material into lightweighting automotive applications can reduce both the embodied and operational environmental burden of a vehicle. These benefits are in alignment with IACMI's sustainability mission.

The fibers trialed in this study were packaged into a format that was feedable with commercially available loss-in-weight gravimetric feeders and standard compounding extrusion equipment. This project demonstrates that recycled fiber performs comparably to virgin in compounding applications. This accessibility for the normally difficult-to-handle recycled material is critical for widespread market adoption.

\section{ACCOMPLISHMENTS}

The project integrated $\mathrm{rCF}$ into a feedable fiber format that was successfully compounded at laboratoryscale. This material was tested to determine the effect of recycling and processing on mechanical properties. Larger volumes of dry fiber were similarly processed and compounded at commercial-scale, allowing for the creation of prototype parts.

The project successfully demonstrated parity between a carbon fiber reinforced thermoplastic compounded from virgin and recycled fibers. Mechanical test results were in close alignment, with the baseline and recycled test specimens shown to share similar property-critical variables (fiber length, etc.) as identified through the theoretical model from Krenchel [8]. Dragonfly ORS was successfully paired with XCT imaging to non-destructively quantify fiber dispersion and alignment in the test specimens. This approach may have future value for theoretical strength calculations or optimization of molded components.

The fiber format was found, qualitatively, to feed well in the larger-scale compounding processes of Task 2 and 3 -avoiding the touchpoint intensive manual handling necessary in Task 1 compounding. This material was used to create complex large geometry commercial parts.

An article [25] was published in the Journal Composites B that covered much of the same material as included in this report as it relates to Task 1. Sections in this report involving Task 1 were reproduced in 
part or in whole from that article. However, the journal article contains additional detail on testing methods and testing results that are not included in this report.

\section{CONCLUSIONS}

The project demonstrated that it is possible to create a recycled fiber compound that performs similarly to a virgin fiber polyamide compound, dramatically increasing the strength and stiffness of the compound relative to the neat thermoplastic.

Single fiber testing for this project found no substantial difference between the fiber strength of recycled and virgin T800S fiber, suggesting that the recycling process was not detrimental to the fiber properties.

Micro-compounding studies showed benefit for the U201 sizing on standard modulus carbon fiber, but sizing was not shown to have a substantial impact on micro-compounded component performance for the intermediate fiber in the format applied. However, the sizing was critical in all three tasks for improving handling characteristics by reducing dust from the friable fibers.

Fiber lengths in the injection molded test specimens were similar between the recycled fiber compound and the baseline compound. Given that recycled fiber lengths were originally much longer than in the final sample, significant fiber length attrition occurred during compounding and molding. For this project, initial fiber length can be expected to have negligible effect on final fiber length and fiber length can be disregarded as a confounding variable for mechanical performance.

SEM and XCT imaging identified similar fiber and void distribution when comparing the baseline test specimen to a recycled fiber test specimen. As such, differences in fiber flow and alignment can be disregarded as confounding variables for specimen performance. Failure mode for both the recycled sample and the baseline, as qualitatively assessed from SEM images of the fracture surface, appeared to occur from de-adhesion between the resin and the fiber. This was expected for short discontinuous composite fiber reinforced plastic. It was determined that Dragonfly ORS could be used to quantify the distribution and alignment of fiber in a sample. This represents a potentially valuable tool when evaluating components and flow for project partners or others in industry.

Creating compound at the $40 \%$ carbon fiber target proved difficult in the small-scale equipment utilized for Task 1 of this project. However, by packaging this fiber into an "agglomerate" with improved binding and bulk density, flow through a commercial loss-in-weight feeder was found to be viable.

When molding test specimens, it was found that higher fiber content material requires additional pressure relative to neat plastics, so full fill is a concern at these higher concentrations. When molded into complex commercial components, it was found that temperature control was especially critical for generating consistent parts as relatively conductive high-carbon filled compound is prone to rapid heat loss. While the results of the molding were inconsistent, given that the utilized tool was not designed specifically for the thermal properties of the compound, those parts that were produced were of high quality. With additional tooling gate modifications, it is believed this compound would process well in the utilized tooling.

In-depth mechanical testing of specimens in Task 1 found that excellent properties (meeting or exceeding milestone targets) could be achieved when using recycled material in a discontinuous short-fiber application. This was reinforced with the Task 2 and 3 findings, where the Ford specification mechanical targets were well-exceeded when using an intermediate modulus fiber. However, the use of a standard modulus fiber would be insufficient to consistently meet specification targets. 
The technical findings in this project make a strong case that injection molding is an appropriate application for recycled/recovered fiber, which lacks the continuous lengths and anisotropy inherent to virgin material and critical for some applications. Strength is maintained while using a less-costly and less environmentally burdensome substitution. Typical objections, notably the feedability of recycled material, can be overcome through additional value-add production steps as used for the material in this project.

\section{RECOMMENDATIONS}

- This project used an early form of a post-processing technology that produces a recycled or recovered carbon fiber that is more easily fed than traditional product forms. Refinement of this process and material has been pursued in parallel at Vartega in partnership with commercial entities and will continue given positive results from this study and others.

- Additional work may be performed to determine how well the theoretical model from Krenchel [8] aligns with results.

- Recycling of some thermoplastics has been shown to detrimentally affect material performance for subsequent reuse applications due to degradation from multiple heat histories. Similarly, fiberreinforced thermoplastic strength may also be reduced due to fiber length attrition during recycling. A study on the practical limit of functional generations of mechanically recycled fiberreinforced thermoplastics may be warranted if not robustly examined in literature at present.

\section{REFERENCES}

[1] J. R. Duflou, J. De Moor, I. Verpoest and W. Dewulf, "Environmental impact analysis of composite use in car manufacturing," CIRP Annals, vol. 58, no. 1, p. 9-12. https://doi.org/10.1016/j.cirp.2009.03.077, 2009.

[2] D. Sunter, W. R. Morrow III, J. Cresko and H. P. Liddell, "The manufacturing energy intensity of carbon fiber reinforced polymer composites and its effect on life cycle energy use for vehicle door lightweighting," in 20th International Conference on Composite Materials, Copenhagen, 2015.

[3] J. Harris, S. Kline, W. L. Jeff, D. Bradley, K. Kooduvalli, A. Frank and D. Brosius, "Closing the loop on automotive carbon fiber prepreg manufacturing scrap - fender case study," in SAMPE Conf. Proc., Seattle, 2020.

[4] Y. Yang, R. Boom, B. Irion, D.-J. van Heerden, P. Kuiper and H. de Wit, "Recycling of composite materials," Chemical Engineering and Processing: Process Intensification, vol. 51, pp. 53-68. https://doi.org/10.1016/j.cep.2011.09.007, 2012.

[5] S. J. Pickering, "Recycling technologies for thermoset composite materials-current status," Composites Part A: Applied Science and Manufacturing, vol. 37, no. 8, pp. 1206-1215. https://doi.org/10.1016/j.compositesa.2005.05.030, 2006.

[6] S. Pimenta and T. P. Silvestre, "Recycling carbon fibre reinforced polymers for structural applications: Technology review and market outlook," Waste Management, vol. 31, no. 2, pp. 378392. https://doi.org/10.1016/j.wasman.2010.09.019, 2011.

[7] S. J. Pickering, T. A. Turner and N. A. Warrior, "Moulding compound development using recycled carbon fibres," in Proc. 38th SAMPE Fall Tech. Conf., 2006. 
[8] H. Krenchel, "Fibre Reinforcement: Theoretical and Practical Investigations of the Elasticity and Strength of Fibre-reinforced Materials," Akademisk forlag, Copenhagen, 1964.

[9] A. Kelly and W. R. Tyson, "Tensile properties of fibre-reinforced metals: Copper/tungsten and copper/molybdenum," Journal of the Mechanics and Physics of Solids, vol. 13, no. 6, pp. 329-338. https://doi.org/10.1016/0022-5096(65)90035-9, 1965.

[10] X. Zhang, Y. Wang, C. Lu and S. Cheng, "Interfacial adhesion study on UHMWPE fiber-reinforced composites," Polymer Bulletin, vol. 67, pp. article 527. https://doi.org/10.1007/s00289-011-0491-2, 2011 .

[11] P. J. Herrera-Franco and A. Valadez-González, "A study of the mechanical properties of short natural-fiber reinforced composites," Composites Part B: Engineering, vol. 36, no. 8, pp. 597-608. https://doi.org/10.1016/j.compositesb.2005.04.001, 2005.

[12] V. B. Gupta, R. K. mittal, P. K. Sharma, G. Mennig and J. Wolters, "Some studies on glass fiberreinforced polypropylene. Part II: Mechanical properties and their dependence on fiber length, interfacial adhesion, and fiber dispersion," Polymer Composites, vol. 10, no. 1, pp. 16-27. https://doi.org/10.1002/pc.750100104, 1989.

[13] M. Shewey, P. Tibbenham and D. Houston, "Carbon Fiber Reinforced Polyolefin Body Panels," IACMI, 2019.

[14] S.-Y. Fu and B. Lauke, "Effects of fiber length and fiber orientation distributions on the tensile strength of short-fiber-reinforced polymers," Composites Science and Technology, vol. 56, no. 10, pp. 1179-1190. https://doi.org/10.1016/S0266-3538(96)00072-3, 1996.

[15] A. Maxey, "US10487191B2 - Recovery of reinforcing fibers from fiber-reinforced composites," US10487191B2, 2019.

[16] ASTM, "C1557 - 20 Standard Test Method for Tensile Strength and Youngs Modulus of Fibers," 2020. https://doi.org/10.1520/C1557-20.

[17] Toray, "T800S Intermediate Modulus Carbon Fiber".

[18] K. Naito, Y. Tanaka, Y. Jm and Y. Kagawa, "Tensile and Flexural Properties of Single Carbon Fibres," 2009.

[19] F. Mesquita, Y. Swolfs, S. Bucknell, Y. Leray, S. V. Lomov and L. Gorbatikh, "Tensile properties of single carbon fibres tested with automated equipment," in TWENTY-SECOND INTERNATIONAL CONFERENCE ON COMPOSITE MATERIALS (ICCM22), Melbourne, 2019.

[20] ISO, "ISO 527-2:2012 - Plastics - Determination of tensile properties - Part 2: Test conditions for moulding and extrusion plastics. https://www.iso.org/standard/56046.html (accessed July 14, 2020)".

[21] ASTM, "D6110 - Standard Test Method for Determining the Charpy Impact Resistance of Notched Specimens of Plastics," 2018. https://doi.org/10.1520/D6110-18. 
[22] BASF, "Ultramid® A3WC8 Polyamide 66," 2020.

[23] Ford, "WRS-M4D1062-A1 - POLYAMIDE (PA66), HEAT STABILIZED, 40\% SHORT CARBON FIBER FILLED, MOLDING COMPOUND, 40\% RECYCLED MATERIAL BY WEIGHT," 2019.

[24] R. A. Witik, R. Teuscher, V. Michaud, C. Ludwig and J.-A. E. Månsona, "Carbon fibre reinforced composite waste: An environmental assessment of recycling, energy recovery and landfilling," Composites Part A: Applied Science and Manufacturing, vol. 49, pp. 88-89. https://doi.org/10.1016/j.compositesa.2013.02.009, 2013.

[25] P. E. Caltagirone, R. S. Ginder, S. Ozcan, K. Li, A. M. Gay, J. Stonecash, K. X. Steirer, D. Cousins, S. P. Kline, A. T. Maxey and A. P. Stebner, "Substitution of virgin carbon fiber with low-cost recycled fiber in automotive grade injection molding polyamide 66 for equivalent composite mechanical performance with improved sustainability," Composites Part B: Engineering, vol. 211, p. https://doi.org/10.1016/j.compositesb.2021.109007, 2021. 